\title{
Chlorotoxin Fused to IgG-Fc Inhibits Glioblastoma Cell Motility via Receptor-Mediated Endocytosis
}

\author{
Tomonari Kasai,, ${ }^{1}$ Keisuke Nakamura, ${ }^{1}$ Arun Vaidyanath, ${ }^{2}$ Ling Chen, ${ }^{3}$ \\ Sreeja Sekhar, ${ }^{1}$ Samah El-Ghlban, ${ }^{1}$ Masashi Okada, ${ }^{1}$ Akifumi Mizutani, ${ }^{1}$ \\ Takayuki Kudoh, ${ }^{1}$ Hiroshi Murakami, ${ }^{1}$ and Masaharu Seno ${ }^{1}$ \\ ${ }^{1}$ Department of Medical and Bioengineering Science, Graduate School of Natural Science and Technology, Okayama University, \\ Okayama 7008530, Japan \\ ${ }^{2}$ Cell and Cancer Biology Branch, National Cancer Institute, National Institutes of Health, Bethesda, MD 20892, USA \\ ${ }^{3}$ Department of Pathology, Tianjin Central Hospital of Gynecology Obstetrics, Tianjin 300100, China
}

Correspondence should be addressed to Masaharu Seno, mseno@okayama-u.ac.jp

Received 30 August 2012; Revised 5 November 2012; Accepted 7 November 2012

Academic Editor: Andreas G. Tzakos

Copyright (C) 2012 Tomonari Kasai et al. This is an open access article distributed under the Creative Commons Attribution License, which permits unrestricted use, distribution, and reproduction in any medium, provided the original work is properly cited.

Chlorotoxin is a 36-amino acid peptide derived from Leiurus quinquestriatus (scorpion) venom, which has been shown to inhibit low-conductance chloride channels in colonic epithelial cells. Chlorotoxin also binds to matrix metalloproteinase- 2 and other proteins on glioma cell surfaces. Glioma cells are considered to require the activation of matrix metalloproteinase- 2 during invasion and migration. In this study, for targeting glioma, we designed two types of recombinant chlorotoxin fused to human IgG-Fcs with/without a hinge region. Chlorotoxin fused to IgG-Fcs was designed as a dimer of $60 \mathrm{kDa}$ with a hinge region and a monomer of $30 \mathrm{kDa}$ without a hinge region. The monomeric and dimeric forms of chlorotoxin inhibited cell proliferation at $300 \mathrm{nM}$ and induced internalization in human glioma A172 cells. The monomer had a greater inhibitory effect than the dimer; therefore, monomeric chlorotoxin fused to IgG-Fc was multivalently displayed on the surface of bionanocapsules to develop a drug delivery system that targeted matrix metalloproteinase-2. The target-dependent internalization of bionanocapsules in A172 cells was observed when chlorotoxin was displayed on the bionanocapsules. This study indicates that chlorotoxin fused to IgG-Fcs could be useful for the active targeting of glioblastoma cells.

\section{Introduction}

Glioblastoma is one of the most malignant and consistently fatal brain cancers in adults. Treatment of glioma remains a challenge largely because of its rapid growth rate and the highly invasive nature of this disease, despite incremental advances in surgical and radiation therapies [1]. Glioma cells are considered to require the activation of matrix metalloproteinase (MMP)-2, which degrades the extracellular matrix $(\mathrm{ECM})$ during invasion and migration $[2,3]$. In the central nervous system, membrane type MMP-1 (MT1MMP) has a more important role than MMP-2 during ECM remodeling, migration, infiltration, and invasion of gliomas [4]. MT1-MMP on cell surfaces is replenished by autodegradation or clathrin-dependent internalization, and its concentration is stabilized by the tissue inhibitor of MMP (TIMP)-2 [5, 6]. Malignant human gliomas express membrane-anchored MMPs and their endogenous TIMPs [7-10]. Many MMP inhibitors have been developed for human clinical trials, but effective candidates have not been obtained $[10,11]$.

Chlorotoxin (CTX) is a 36-amino acid peptide with four disulfide bridges and is derived from Leiurus quinquestriatus (scorpion) venom. CTX has been shown to inhibit low-conductance chloride channels in colonic epithelial cells [12]. Several experiments have used CTX to target brain tumors, exploiting its binding affinity to the gliomaspecific chloride ion channel complex, MMP-2, and other 
proteins $[13,14]$. Recently, a conjugate of CTX and fluorescent dye was demonstrated to target brain tumors by visualizing cancer foci in vivo $[15,16]$.

Bionanocapsules (BNCs) are artificial hollow nanoparticles composed of the recombinant envelope L protein of hepatitis B virus, which has a specific affinity for human hepatocytes $[17,18]$. To confer BNCs a high affinity for the IgG-Fc domain, the pre-S1 region of $\mathrm{L}$ protein was replaced with the $\mathrm{ZZ}$ motif in protein A derived from Staphylococcus aureus $[19,20]$. BNCs displaying anti-human EGFR monoclonal antibodies were delivered successfully to glioma cells in a mouse model of brain tumors [19]. EGFR is expressed not only in tumors but also in normal epithelia; therefore, it may not always be feasible to target brain tumors with EGFR. Thus, we designed a CTX peptide fused to the human IgG-Fc domain (CTX-Fc) in this study to establish a more efficient and specific targeting vehicle for glioblastoma cells.

\section{Materials and Methods}

2.1. Cell Culture. A human cell line derived from glioblastoma, A172 (RCB2530), was provided by RIKEN BRC through the National BioResource Project of MEXT, Japan. Glioma cells were grown and subcultured in RPMI medium (Sigma-Aldrich, St Louis, MO, USA) supplemented with $10 \%$ fetal bovine serum (FBS, PAA Laboratories, Pasching, Austria) in the presence of $100 \mathrm{IU} / \mathrm{mL}$ penicillin and $100 \mu \mathrm{g} / \mathrm{mL}$ streptomycin (Nacalai Tesque, Kyoto, Japan). The cells were maintained at $37^{\circ} \mathrm{C}$ in a humidified incubator with $95 \%$ air and $5 \% \mathrm{CO}_{2}$.

2.2. Construction of Expression Plasmids. The expression plasmids for CTX fused to human IgG-Fcs (CTX-Fcs) were constructed as follows. An oligonucleotide coding for the CTX peptide was synthesized by Operon Biotechnologies (Tokyo, Japan) and cloned into pET28b (Novagen, Darmstadt, Germany). The DNA fragment coding human IgG-Fcs was excised from the plasmid pBO593 (coding with a hinge domain) and pBO807 (coding without a hinge domain, $[20,21])$ using the restriction endonucleases, AgeI and NotI, and then ligated to the $3^{\prime}$-end of the CTX coding sequence downstream of a T7 promoter to code a dimeric form of CTX-Fc (D-CTX-Fc) and a monomeric form of CTX-Fc (MCTX-Fc), respectively.

2.3. Expression and Purification of M/D-CTX-Fcs. Escherichia coli BL21 (DE3) pLysS (Novagen) was transformed with expression vectors for M/D-CTX-Fcs. Transformants were grown in $1 \mathrm{~L}$ of $\mathrm{LB}$ medium containing $50 \mu \mathrm{g} / \mathrm{mL}$ kanamycin and $10 \mu \mathrm{g} / \mathrm{mL}$ chloramphenicol at $37^{\circ} \mathrm{C}$. Protein expression was induced by $0.4 \mathrm{mM}$ isopropyl 1thio- $\beta$-D-galactopyranoside. After expression induction, the transformants were cultured at $25^{\circ} \mathrm{C}$ for $16 \mathrm{~h}$, and the bacteria were harvested. Cell pellets were thawed and homogenized in $20 \mathrm{~mL}$ of lysis buffer containing $10 \mathrm{mM}$ Tris$\mathrm{HCl}$ ( $\mathrm{pH} 8.0$ ), $10 \mathrm{mM}$ EDTA, $0.2 \mathrm{M} \mathrm{NaCl}$, and $10 \%$ sucrose. The inclusion bodies were collected by centrifugation at
$12,000 \times \mathrm{g}$ for $20 \mathrm{~min}$. The inclusion bodies were washed three times with $0.5 \%$ Triton X-100. The insoluble fraction was resolved in $4 \mathrm{~mL}$ of $6 \mathrm{M}$ guanidinium $\mathrm{HCl}$ containing $0.1 \mathrm{M}$ Tris- $\mathrm{HCl}$ ( $\mathrm{pH}$ 8.5). The solution was degassed by aspiration while purging the air with nitrogen gas and supplemented with $50 \mu \mathrm{L}$ of 2 -mercaptoethanol. After $1 \mathrm{~h}$ incubation at $37^{\circ} \mathrm{C}$ in a shaking water bath, the mixture was dispersed into a 20 -fold volume of refolding buffer containing $10 \mathrm{mM}$ Tris- $\mathrm{HCl}(\mathrm{pH} 8.5), 0.1 \mathrm{M} \mathrm{NaCl}$, and $0.5 \mathrm{mM}$ oxidized glutathione. Refolding was conducted by incubation at $4^{\circ} \mathrm{C}$ for $18 \mathrm{~h}$. The $\mathrm{pH}$ was then adjusted to 7.0 using acetic acid. Insoluble materials were removed by centrifugation at $12,000 \times \mathrm{g}$ for $20 \mathrm{~min}$. The solution containing refolded protein was applied to a cobalt resin column (TALON superflow metal affinity resin, Clontech, Mountain View, CA, USA), after equilibrating with equilibration buffer containing $50 \mathrm{mM}$ phosphate buffer $(\mathrm{pH}$ 7.0) and $300 \mathrm{mM} \mathrm{NaCl}$. The column was then washed with equilibration buffer containing $20 \mathrm{mM}$ imidazole and $0.1 \%$ Triton X-100. M/D-CTX-Fcs were eluted with elution buffer containing $50 \mathrm{mM}$ phosphate buffer ( $\mathrm{pH}$ 7.0), $300 \mathrm{mM}$ imidazole, and $300 \mathrm{mM} \mathrm{NaCl}$. The eluted solution was dialyzed three times against phosphate-buffered saline (Dulbecco's formula, hereafter PBS) for $2 \mathrm{~h}$ each time. The purity of M/D-CTX-Fcs in the final preparations was assessed by SDS-PAGE, Coomassie Brilliant Blue (CBB) staining, and western blotting.

2.4. Preparation of CTX-Fc-BNCs. We mixed $2 \mathrm{nM}(10 \mu \mathrm{g} /$ $\mathrm{mL})$ ZZ-tagged bionanocapsules (ZZ-BNCs) [19] with MCTX-Fc or human IgG (Sigma-Aldrich) at a ratio of $1: 20$ and incubated them at $4{ }^{\circ} \mathrm{C}$ for $1 \mathrm{~h}$ in PBS. The precipitates were removed by centrifugation at $12,000 \times \mathrm{g}$ for $5 \mathrm{~min}$.

2.5. Enzyme Immunoassay on Cell Surfaces. The enzyme immunoassay (EIA) was designed to evaluate the binding ability of CTX-Fcs to A172 cell surfaces. Each well of a 96-well plate (Greiner Bio-One, Frickenhausen, Germany) was coated with $10 \%$ skim milk (Wako Pure Chemical Industries, Osaka, Japan) in PBS at $25^{\circ} \mathrm{C}$ for $1 \mathrm{~h}$ and washed with PBS. Five thousand A172 cells/well were seeded in RPMI medium supplemented with $10 \%$ FBS, $100 \mathrm{IU} / \mathrm{mL}$ penicillin, and $100 \mu \mathrm{g} / \mathrm{mL}$ streptomycin. After $20 \mathrm{~h}$ of culture, the cells were washed three times with PBS and fixed with $4 \%$ paraformaldehyde in PBS. The cells were washed three times with PBS, covered with $10 \%$ skim milk in PBS at $25^{\circ} \mathrm{C}$ for $1 \mathrm{~h}$, and then washed three times with PBS. The cells were incubated with M/D-CTX-Fcs in a range of 0 $400 \mathrm{nM}$ in PBS at $25^{\circ} \mathrm{C}$ for $1 \mathrm{~h}$. The cells were then washed with PBS containing $0.1 \%$ Tween-20 (PBST), before adding $100 \mu \mathrm{L}$ of protein A conjugated to horse radish peroxidase (HRP; Sigma-Aldrich), diluted to 1:500, and incubated at $25^{\circ} \mathrm{C}$ for $1 \mathrm{~h}$. The wells were washed three times with PBST, and $100 \mu \mathrm{L} 3,3^{\prime}, 5,5^{\prime}$-tetramethylbenzidine (TMB) Liquid Substrate System (Sigma-Aldrich) was added to test the peroxidase reaction. After $5 \mathrm{~min}$, the reaction was quenched with $50 \mu \mathrm{L}$ of $0.5 \mathrm{M}$ sulfuric acid, and the absorbance at $450 \mathrm{~nm}$ was measured in each well using a microplate reader 
(SH-9000; Corona Electric, Ibaraki, Japan). Each experiment was performed in triplicate, and the mean values and standard deviations were calculated.

2.6. Wound Healing Assay. Thirty thousand A172 cells were seeded into a 24-well plate in RPMI medium supplemented with $10 \% \mathrm{FBS}, 100 \mathrm{IU} / \mathrm{mL}$ penicillin, and $100 \mu \mathrm{g} / \mathrm{mL}$ streptomycin. After $20 \mathrm{~h}$ incubation, each confluent monolayer was scratched using a $200 \mu \mathrm{L}$ plastic pipette tip to create a wounded cell-free area and washed with RPMI medium supplemented with $10 \%$ FBS. The cells were incubated at $37^{\circ} \mathrm{C}$ with $\mathrm{M} / \mathrm{D}-\mathrm{CTX}-\mathrm{Fcs}$ in a range of $0-300 \mathrm{nM}$ in RPMI medium supplemented with $10 \% \mathrm{FBS}, 100 \mathrm{IU} / \mathrm{mL}$ penicillin, and $100 \mu \mathrm{g} / \mathrm{mL}$ streptomycin and photographed at 0 and $12 \mathrm{~h}$ using an inverted microscope CKX41 (Olympus, Tokyo, Japan). The digital images were acquired with a digital camera U-CMDA3 (Olympus) using the imaging program DP2-BSW (Olympus). The distances between the edges of cell-free areas were measured using NIH Image J. The migration length was defined as the change in the distance between 0 and $12 \mathrm{~h}$, which was normalized by the change in the absence of the stimulant.

2.7. Cell Migration Assay. The migration of A172 cells was assayed in 24 -well plates with $8 \mu \mathrm{m}$ pore cell culture inserts (BD, Franklin Lakes, NJ, USA). Five hundred microliters of RPMI medium supplemented with $10 \%$ FBS were added to each well, and $3 \times 10^{4}$ cells were seeded into each insert. The cells were incubated with M/D-CTX-Fcs in a range of 0-300 $\mathrm{nM}$ in RPMI medium supplemented with 1\% BSA at $37^{\circ} \mathrm{C}$. After $48 \mathrm{~h}$ of culture, the insert chambers were removed, and adherent cells on the bottom of each well were counted. The number of migrated cells was normalized by the number of adherent cells in the absence of CTX-Fcs.

2.8. Cell Proliferation Assay. The inhibition of cell growth by M/D-CTX-Fcs was evaluated using a 3-(4, 5-dimethylthiazol-2-yl)-2, 5-diphenyltetrazolium bromide (MTT) cleavage assay with A172 cells. The cells were seeded at $5 \times 10^{3}$ cells/well in 96-well plates in RPMI medium supplemented with $10 \%$ FBS. After $20 \mathrm{~h}$ of culture, M/D-CTX-Fcs in a range of $0-300 \mathrm{nM}$ were added in triplicate, and the cells were further cultured for $48 \mathrm{~h}$. The cells were then exposed to $5 \mathrm{mg} / \mathrm{mL}$ MTT in PBS at a final concentration of $1 \mathrm{mg} / \mathrm{mL}$ in culture for $5 \mathrm{~h}$. Formazan crystals formed during the incubation period were dissolved overnight at $37^{\circ} \mathrm{C}$ by adding $10 \%$ SDS containing $20 \mathrm{mM} \mathrm{HCl}$. The absorbance was measured at $570 \mathrm{~nm}$. To assess the viability of cells treated with CTX after $48 \mathrm{~h}$ incubation with different concentrations of CTX, the wells were washed twice with RPMI medium supplemented with 10\% FBS. The cells were further incubated for $24 \mathrm{~h}$ in RPMI medium supplemented with $10 \%$ FBS. The viable cells were evaluated using the MTT cleavage assay, as described above.

2.9. Confocal Microscopic Observation. For confocal microscopic observation, A172 cells were grown on $18 \mathrm{~mm}$ cover slips (Iwaki, Tokyo, Japan) in 12-well plates. The cells were incubated with $30 \mathrm{nM}$ M/D-CTX-Fcs or $30 \mathrm{nM}$ human
IgG-Fc domain [20] in PBS containing 1\% BSA for 15 min or $1 \mathrm{~h}$ at $4^{\circ} \mathrm{C}$ or $37^{\circ} \mathrm{C}$. The cells were washed twice with PBS to evaluate specific binding to cell surfaces. The cells were fixed with $4 \%$ paraformaldehyde in PBS, permeabilized with $0.2 \%$ Triton X-100, and blocked with blocking solution containing $10 \%$ FBS or $1 \%$ BSA in PBS. The cells were washed with PBS and incubated with anti-early endosome antigen-1 (EEA-1) antibody (Cell Signaling Technology, Beverly, MA, USA) for $1 \mathrm{~h}$ at $25^{\circ} \mathrm{C}$ followed by Alexa 555labelled anti-rabbit IgG (Molecular Probes Inc., Eugene, OR, USA) for $30 \mathrm{~min}$ at $25^{\circ} \mathrm{C}$. The cells were washed with PBS and incubated with FITC-labeled anti-human IgG-Fc antibody (Sigma-Aldrich) for $30 \mathrm{~min}$ at $25^{\circ} \mathrm{C}$. After further washes, the nuclei were stained with DAPI (Vector Laboratories Inc., Burlingame, CA, USA), and the cells were visualized using a confocal microscope IX81 (Olympus) with Fluoview FV1000 (Olympus). To observe the binding of BNCs on cells, the cells were incubated with CTX-Fc-BNCs at $37^{\circ} \mathrm{C}$ for $1 \mathrm{~h}$. The specific binding of CTX-Fcs was further assessed by competition with a CTX (Sigma-Aldrich). In the competitive assay, the cells were incubated primarily with $300 \mathrm{nM}$ CTX in $1 \%$ BSA-PBS at $4^{\circ} \mathrm{C}$ for $20 \mathrm{~min}$, followed by incubation with CTX-Fc-BNCs in the presence of $300 \mathrm{nM}$ CTX at $37^{\circ} \mathrm{C}$ for $1 \mathrm{~h}$. The cells were washed with PBS and fixed with $4 \%$ paraformaldehyde in PBS, permeabilized with $0.2 \%$ Triton X-100, and blocked with blocking buffer. The cells were washed with PBS and incubated with anti-human IgGFc antibody labeled with fluorescein isothiocyanate (FITC) (Sigma-Aldrich) for $1 \mathrm{~h}$ at $25^{\circ} \mathrm{C}$. After further washes, the cells were visualized using a confocal microscope LSM 510 Meta (Carl Zeiss, Jena, Germany) equipped with an argon laser having an excitation laser line of $488 \mathrm{~nm}$ coupled with a bandpass filter of $505 \mathrm{~nm}$.

2.10. Assessment of Internalization of CTX-Fc-BNCs. Cellular uptake of CTX-Fc-BNCs was evaluated. A172 cells in 60$\mathrm{mm}$ dishes were washed three times with ice-cold PBS and incubated with $2 \mathrm{nM}(10 \mu \mathrm{g} / \mathrm{mL})$ of CTX-Fc-BNCs, human IgG-BNCs, or M-CTX-Fc for $1 \mathrm{~h}$ at $4^{\circ} \mathrm{C}$ or $37^{\circ} \mathrm{C}$. After incubation, the cells were washed three times with icecold PBS to remove unbounded BNCs and were collected by treatment with $0.025 \%$ trypsin. After centrifugation at $5000 \times \mathrm{g}$ for $5 \mathrm{~min}$, the supernatant was discarded, and the cell pellet was washed three times with ice-cold PBS. The cells were then lysed in lysis buffer, incubated for $20 \mathrm{~min}$ on ice, and sonicated twice. The extracts were clarified by centrifugation at $12,000 \times \mathrm{g}$ for $5 \mathrm{~min}$ at $4^{\circ} \mathrm{C}$. Twenty microliters of anti-HBsAg microbead suspension were added to the extracts, and this mixture was incubated overnight at $4^{\circ} \mathrm{C}$. After centrifugation at $12,000 \times \mathrm{g}$ for $30 \mathrm{~s}$ at $4^{\circ} \mathrm{C}$, the beads were washed three times in PBS, suspended in Laemmli buffer supplemented with $\beta$-mercaptoethanol, heated for $5 \mathrm{~min}$ at $95^{\circ} \mathrm{C}$, and subjected to SDS-PAGE followed by western blotting.

2.11. Western Blotting and Image Analysis. Proteins resolved on SDS-PAGE were transferred to a polyvinylidene difluoride (PVDF) membrane (Millipore, Billerica, MA, USA). The membrane was blocked with $10 \%$ skim milk in $10 \mathrm{mM}$ 


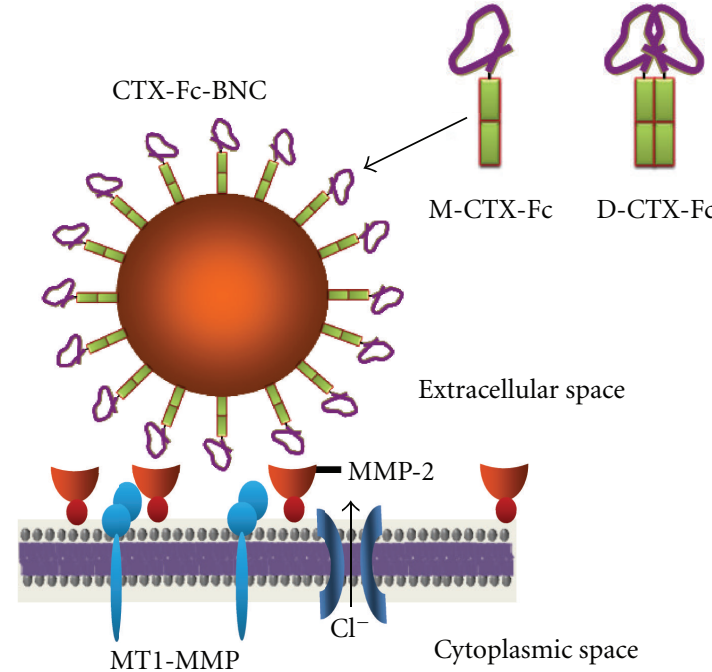

(a)

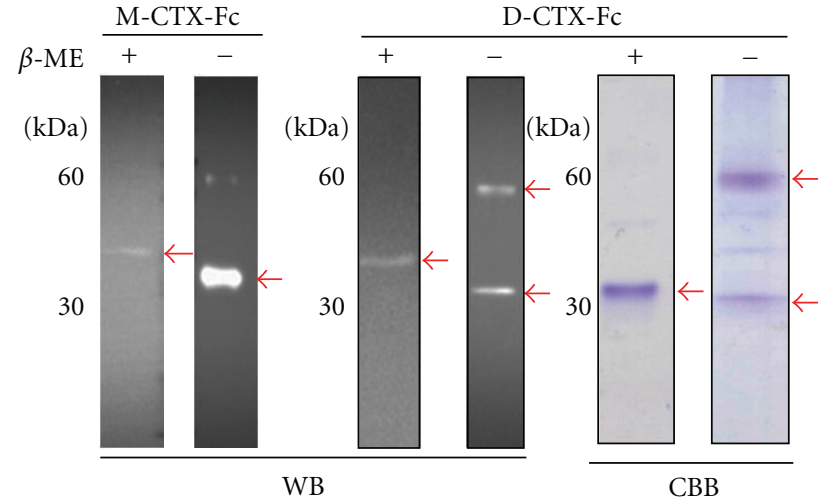

(b)

Figure 1: Design and preparation of M/D-CTX-Fcs. (a) Schematic diagrams of monomeric and dimeric CTX-Fcs and the multivalent display of M-CTX-Fc on the surface of ZZ-BNCs. (b) Reduced and nonreduced forms of M/D-CTX-Fcs. M/D-CTX-Fcs were subjected to SDS-PAGE and western blotting. Anti-human-IgG-Fc antibody reacted with the purified M/D-CTX-Fcs without significant degradation. Arrows indicate the purified protein. $\beta$-ME: beta-mercaptoethanol; WB: western blotting; CBB: Coomassie Brilliant Blue staining.

Tris- $\mathrm{HCl}$ (pH 7.4), $150 \mathrm{mM} \mathrm{NaCl}$ containing $0.1 \%$ Tween20 (TBST). The blots were probed with anti-human IgG mouse monoclonal antibody conjugated with HRP (Life technologies, Carlsbad, CA, USA) diluted to 1:500 in TBST containing 10\% skim milk. The HRP signal was developed using a Western Lightning Plus-ECL chemiluminescence reagent (PerkinElmer, Waltham, MA, USA), and the intensities of the bands were visualized using a Light-Capture II cooled CCD camera system (ATTO, Tokyo, Japan). The relative intensities of the blots were quantitatively analyzed using NIH Image J.

2.12. Statistical Analysis. The results were expressed as means \pm standard deviations from at least three independent experiments. The data were analyzed using Student's $t$-test. $P<0.05$ was considered statistically significant.

\section{Results}

3.1. Preparation of $M / D-C T X-F c s$. Schematic representations of M/D-CTX-Fcs and ZZ-BNCs displaying M-CTXFcs are shown in Figure 1(a). The His-tagged CTX-Fc fusion protein was designed as a CTX peptide fused to the amino terminus of the human IgG-Fc domain with/without a hinge domain. The CTX-Fcs expressed in E. coli were observed as monomers of approximately $30 \mathrm{kDa}$ under the reducing condition, whereas CTX-Fcs with a hinge domain were observed as dimers of approximately $60 \mathrm{kDa}$ under the nonreducing condition, which was confirmed using $\mathrm{CBB}$ staining or western blotting (Figure 1(b)).

3.2. Intracellular Localization of M/D-CTX-Fcs in A172 Cells. Because of the high expression levels of MMP-2 [22], we evaluated the binding capabilities of M/D-CTX-Fcs on the surface of A172 glioblastoma cells. When the cells were incubated with M/D-CTX-Fcs at $4^{\circ} \mathrm{C}$, the fluorescence from anti-human IgG labeled with FITC indicated the localization of the fused proteins on the plasma membrane. However, when the cells were incubated at $37^{\circ} \mathrm{C}$, the fluorescence indicated that M/D-CTX-Fcs were localized intracellularly in A172 cells (Figure 2(a)). In contrast, the human IgG-Fc domain without a CTX domain produced no fluorescence at $4^{\circ} \mathrm{C}$ or $37^{\circ} \mathrm{C}$ indicating the specific binding of the CTX moiety to A172 cell surfaces (see Figure S1 in Supplementary Materials available online at doi:10.1155/2012/975763). We quantitatively evaluated the cell surface binding affinity by assaying sequentially diluted M/D-CTX-Fcs using the A172 cells fixed in EIA plates. The results showed that M-CTX-Fc had a higher affinity than D-CTX-Fc and that $100 \mathrm{nM}$ of MCTX-Fc saturated the binding (Figure 2(b)).

3.3. Effect of M/D-CTX-Fcs on the Migration of A172 Cells. The effect of M/D-CTX-Fcs on the migration of A172 cells was assessed (Figure 3(a)). Although M-, D-CTX-Fcs, and CTX at a concentration of $300 \mathrm{nM}$ significantly inhibited the migration of the cells, M-CTX-Fc exhibited the inhibition clearly depending on the concentration. In the wound healing assay, the effect of inhibition by both $\mathrm{M}$ - and $\mathrm{D}$ CTX-Fcs appeared to be dose dependent in the range of 3$300 \mathrm{nM}$ (Figure 3(b)). The results showed that M-CTX-Fc had a more efficient inhibitory effect than D-CTX-Fc.

We then evaluated the effects of M/D-CTX-Fcs on the proliferation and viability of A172 cells. M-CTX-Fc strongly suppressed the cell viability compared with D-CTX-Fc and CTX (Figure 4(a)). IC 50 was estimated at around $100 \mathrm{nM}$. After treatment with $300 \mathrm{nM} \mathrm{M} / \mathrm{D}-\mathrm{CTX}-\mathrm{Fcs}$ for $48 \mathrm{~h}$, the growth of cells resumed in the next $24 \mathrm{~h}$ when the medium 

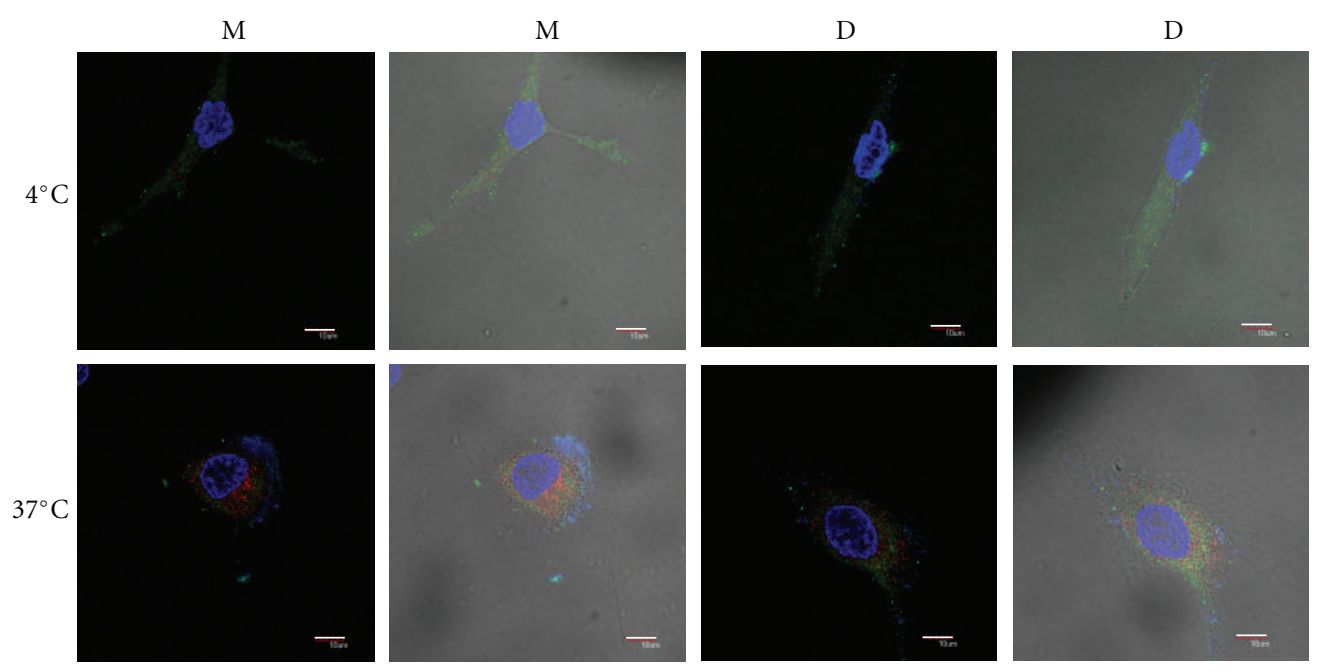

(a)

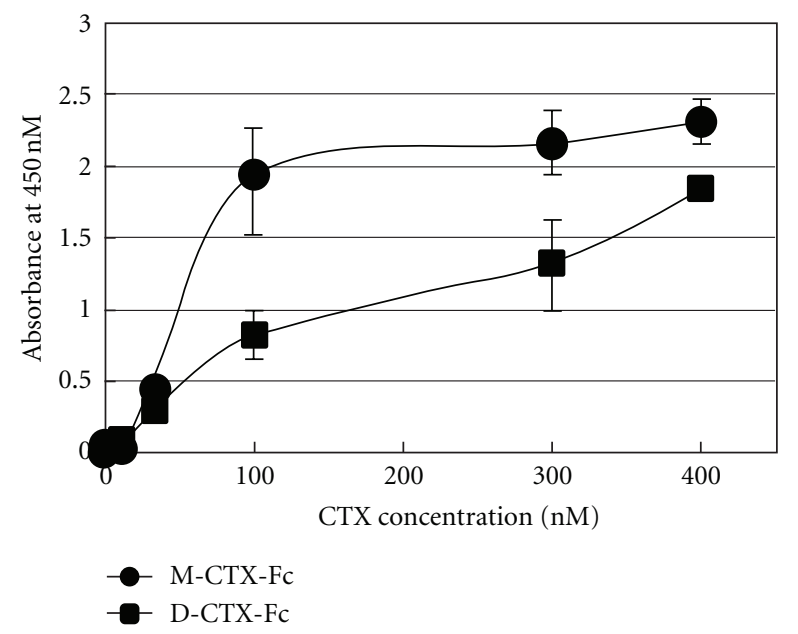

(b)

Figure 2: Immunofluorescence image and binding assay for M/D-CTX-Fcs using A172 cells. (a) The M/D-CTX-Fcs attached to cell surfaces at $4^{\circ} \mathrm{C}$ (upper). Fifteen minutes incubation at $37^{\circ} \mathrm{C}$ promoted the internalization of M/D-CTX-Fcs into cells (lower). The cells were stained with anti-human IgG antibody labeled with FITC, anti-EEA1 antibody and anti-rabbit IgG antibody labeled with alexa-555, and DAPI. Left: fluorescence image; right; composite image. M: M-CTX-Fc; D: D-CTX-Fc. Bars $=10 \mu \mathrm{m}$. (b) The binding ability of M/D-CTX-Fcs was evaluated by EIA. A172 cells were fixed on EIA plates and exposed to M/D-CTX-Fcs. The affinity of M-CTX-Fc for cell surfaces was higher than that of D-CTX-Fc.

was replaced with a medium without M/D-CTX-Fcs or CTX (Figure 4(b)).

3.4. Internalization of CTX-Fc-BNCs. The M-CTX-Fc was multivalently displayed on the surface of ZZ-BNCs, thereby exploiting the affinity of the $\mathrm{ZZ}$ peptide for the IgG-Fc region [20]. CTX-Fc-BNCs $(2 \mathrm{nM}, 10 \mu \mathrm{g} / \mathrm{mL})$ were incubated with A172 cells at $37^{\circ} \mathrm{C}$ for $1 \mathrm{~h}$, and the specific binding of CTX-Fc-BNCs was observed competing with free CTX (Figure 5(a)). To evaluate the internalization of CTX-FcBNCs, the cells were incubated with M-CTX-Fc, human IgGBNCs, or CTX-Fc-BNCs at $37^{\circ} \mathrm{C}$ or $4^{\circ} \mathrm{C}$. The incubation of cells at $37^{\circ} \mathrm{C}$ facilitated the intracellular localization of BNCs, indicating that the temperature-dependent internalization was attributable to a membrane-dependent mechanism (Figures 5(b) and 5(c)).
The mechanism of uptake of CTX-Fc-BNCs was assessed in A172 cells using endocytotic pathway inhibitors (Figure 6). To determine the effective concentration of CPZ, the cells were incubated with $2 \mathrm{nM}$ of CTX-Fc-BNCs and CPZ in the range of 0-100 nM (Vaidyanath et al. 2011 [20], Figure S2). One hundred nanomolar of CPZ effectively inhibited the internalization of CTX-Fc-BNCs in A172 cells. The cells were treated with $\mathrm{CPZ}$, an amphiphilic drug that inhibits the clathrin-mediated pathway, and the internalization of CTX-Fc-BNCs was reduced to the same level as that of human IgG-BNCs.

\section{Discussion}

Migration of glioma cells is considered to be correlated with MMP-2 expression and activity [2, 3]. Membrane-associated 


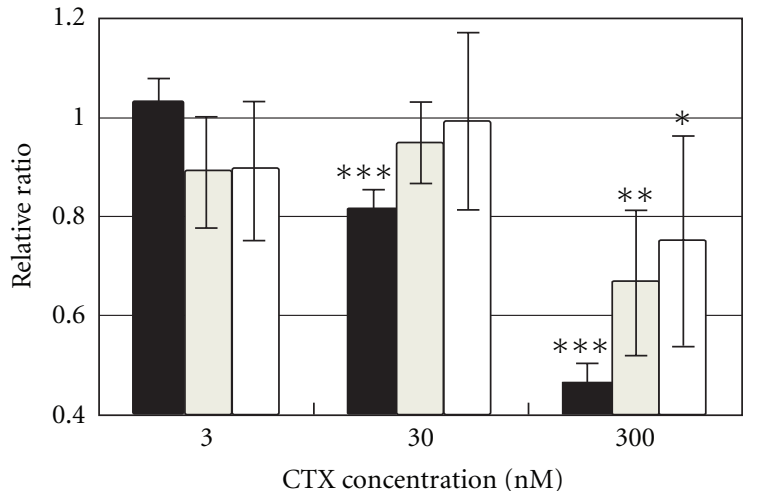

- M-CTX-Fc

$\square$ D-CTX-Fc

$\square$ CTX

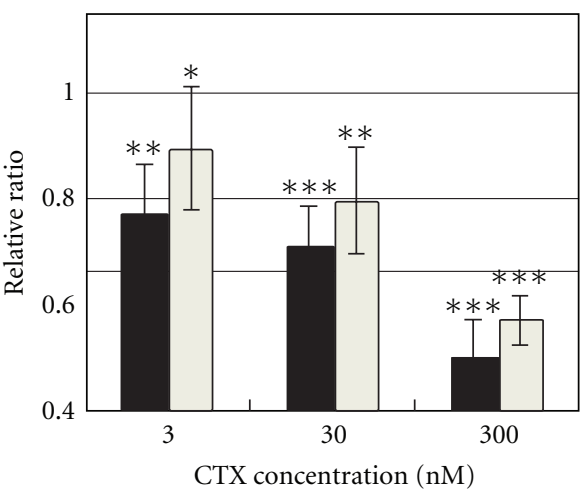

M-CTX-Fc $\square$ D-CTX-Fc

(a)

(b)

Figure 3: Cell migration and wound healing assays. (a) The effect of M/D-CTX-Fcs on the migration of A172 cells was assessed using a PET track-etched membrane culture insert (pore size, $8.0 \mu \mathrm{m}$ ). The cells were incubated with M/D-CTX-Fcs in the range of $0-300 \mathrm{nM}$. Translocated cell numbers were normalized against those in the absence of CTX. The results are shown as means \pm SD. (b) The inhibition of cell migration by M/D-CTX-Fcs was assayed by wound healing. The effect on migration was evaluated based on the change in the distance. The data (mean \pm S.D) presented are from three independent experiments. $\left({ }^{*} P<0.1,{ }^{* *} P<0.05\right.$, $\left.{ }^{* * *} P<0.01\right)$.

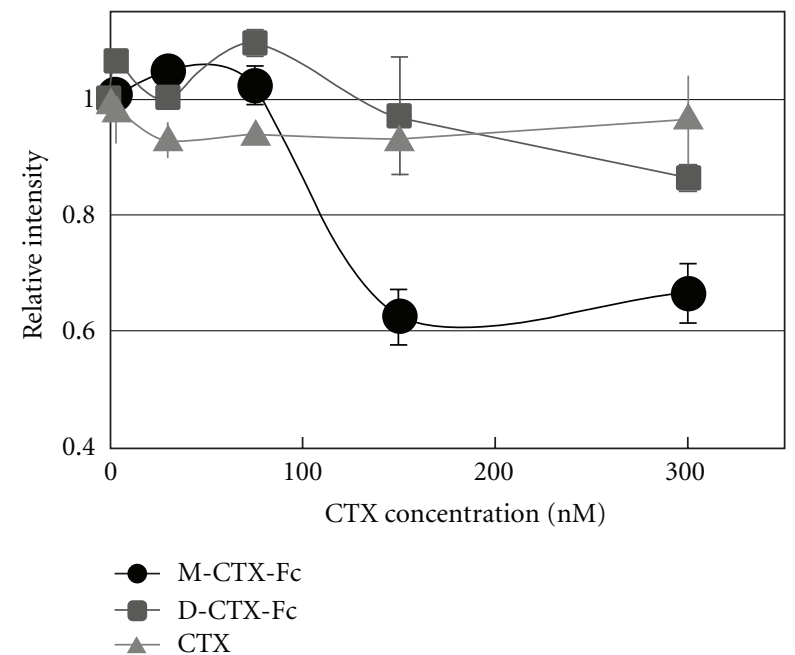

(a)

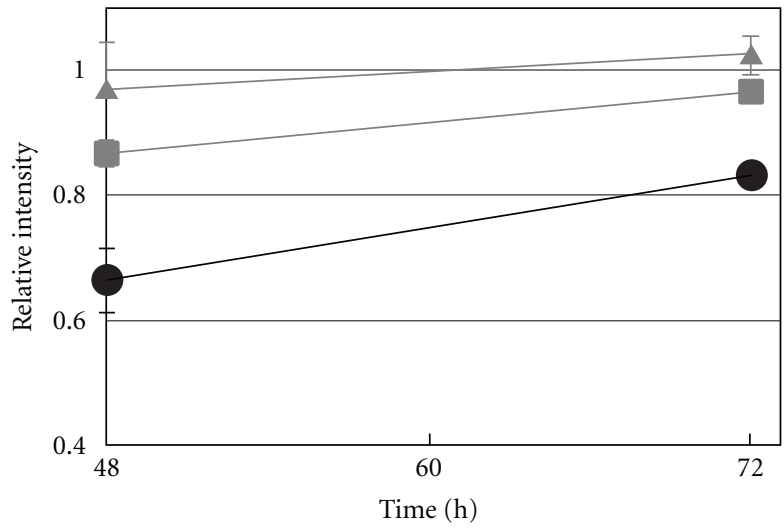

- M-CTX-Fc
- D-CTX-Fc
- CTX

(b)

FIgure 4: Proliferation inhibition activity. (a) The inhibition of cell growth in the presence of M/D-CTX-Fcs for $48 \mathrm{~h}$. (b) The viable cells at $48 \mathrm{~h}$ were kept cultured without M/D-CTX-Fcs up to $72 \mathrm{~h}$. Cell numbers in each well were assessed by MTT assay. The absorbance at $570 \mathrm{~nm}$ corresponding to the initial number of the cells was defined as 1.

MT1-MMP mediates proteolysis and activates the precursor of MMP-2 (pro-MMP-2), which localizes on the cell surface, and these events occur at the invasive edge of tumor cell nests $[6,23,24]$. Most MMPs have a hemopexin C-terminal domain ( $\mathrm{C}$ domain), which is linked to the $\mathrm{C}$ terminus of the catalytic domain via a flexible proline-rich linker peptide [25-27]. It is considered that MMP-2 contributes to migration, invasion, translocation, and malignancy. In glioma cells, it was reported that CTX inhibits cell invasion by reducing MMP2 activity [13]. In addition, MMP-2 is associated with cell signaling by binding to integrins directly. The proteolytically activated form of the $\mathrm{C}$ terminus of
MMP-2 can bind integrins on melanoma cells and blood vessels [28]. An angiogenic regulator, angiopoietin 2, induces invasion by stimulating MMP-2 expression and secretion in glioma cells [29]. In cancer, MMPs, such as MMP-2 and MT1-MMP, associate with tumor growth, tissue remodeling, tissue invasion, and metastasis. We designed and purified M/D-CTX-Fcs (Figure 1). M/D-CTX-Fcs were attached to A172 cell surfaces, and they localized intracellularly at $37^{\circ} \mathrm{C}$ (Figure 2). Furthermore, M/D-CTX-Fcs inhibited cell migration and proliferation in a dose-dependent manner (Figures 3 and 4). Collectively, CTX was shown to inhibit and arrest the cell proliferation machinery but without being 
CTX-Fc-BNCs
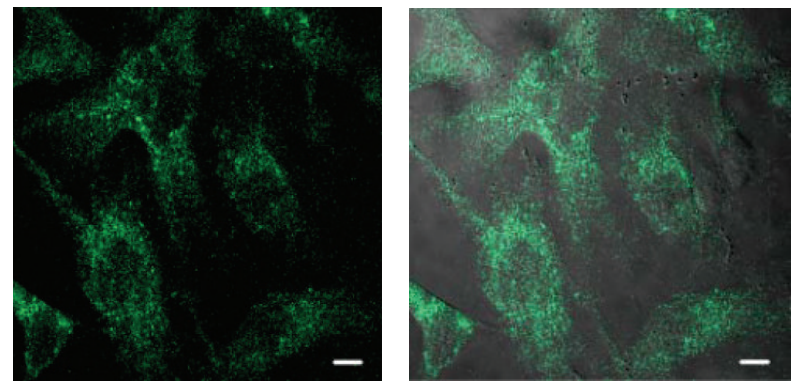

CTX competition
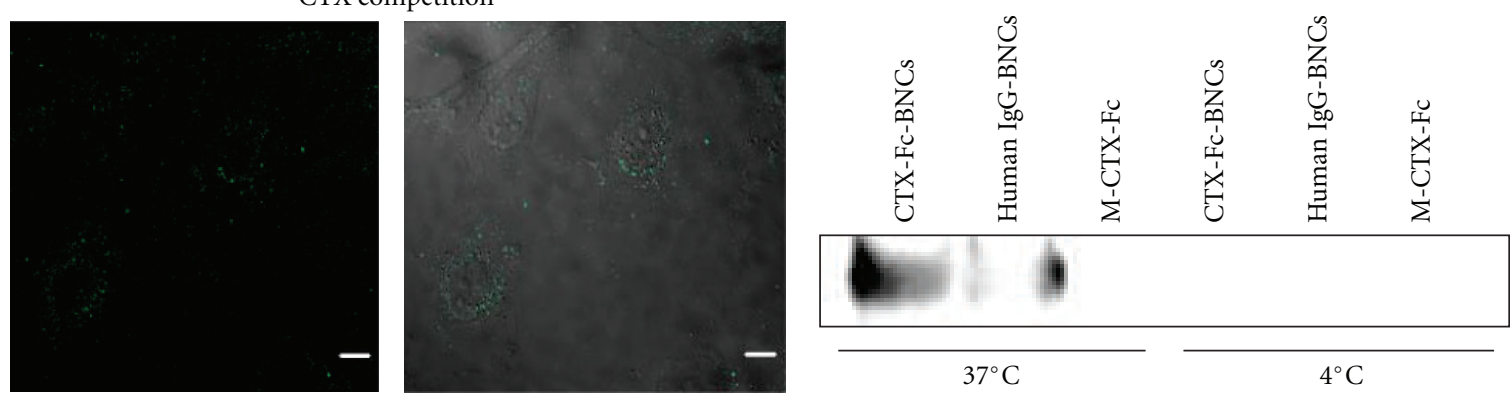

(a)

(b)

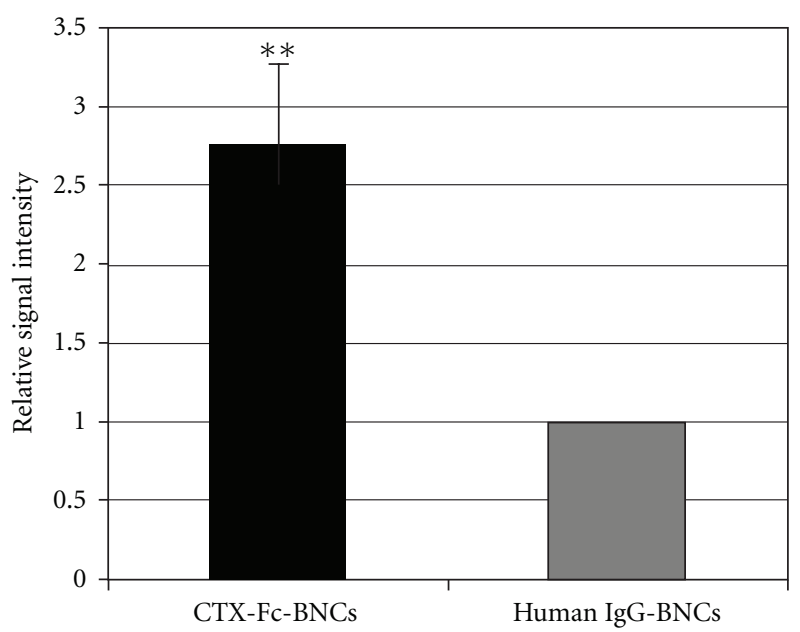

(c)

Figure 5: Evaluation of CTX-Fc-BNCs internalized by A172 cells. (a) A172 cells were incubated with CTX-Fc-BNCs at $37^{\circ} \mathrm{C}$. In "CTX competition", the cells were treated primarily with CTX at $4^{\circ} \mathrm{C}$ for $20 \mathrm{~min}$ before incubating with CTX-Fc-BNCs. The cells were stained with anti-human IgG antibody labeled with FITC. Left: fluorescence image; right; composite image. Bars $=10 \mu \mathrm{m}$. (b) and (c) A172 cells were treated with CTX-Fc-BNCs, human IgG-BNCs, or M-CTX-Fc for $1 \mathrm{~h}$ at $4^{\circ} \mathrm{C}$ or $37^{\circ} \mathrm{C}$. After incubation, the cells were trypsinized. The cytoplasmic fraction was immunoprecipitated with anti-HBsAg antibody conjugated to microbeads. (b) The precipitates were immunoblotted and detected with anti-human-IgG-Fc antibody. (c) The BNC bands in the CTX-Fc-BNCs or human IgG-BNCs treatment at $37^{\circ} \mathrm{C}$ were analyzed densitometrically using a CS Analyzer 3.0 and plotted in each graph to estimate the amount endocytosed. The data $\left(\right.$ mean \pm S.D) presented are from three independent experiments $\left({ }^{* *} P<0.05\right)$.

toxic to the cells (Figure 4(b)). These findings suggest that M/D-CTX-Fcs may be a potential ligand for the active targeting of glioblastoma cells.

Several MMPs are considered to regulate signaling pathways in cells [30]. MT1-MMP influences the cellular microenvironment and promotes cell invasion via degradation of ECM, shedding of CD44 and syndecan1, and activation of ERK, Akt, and FAK signaling [31, 32]. MT1MMP is internalized, and like other membrane-binding molecules, it is regulated by endocytosis because of the functional role of internalization in the cytoplasmic tail [33]. The regulation of the activity and internalization of MT1MMP are associated with integrin on endothelial cells [34]. Endocytosis and accumulation of MT1-MMP are mediated by the clathrin-dependent endocytic pathway [33]. CTXFc-BNCs were localized intracellularly at $37^{\circ} \mathrm{C}$ (Figure 5), which was inhibited by $100 \mathrm{nM} \mathrm{CPZ,} \mathrm{a} \mathrm{blocker} \mathrm{of} \mathrm{clathrin-}$ coated pit formation [21], and by $5 \mathrm{mM} \mathrm{m} \beta \mathrm{CD}$ (Figure 6), 


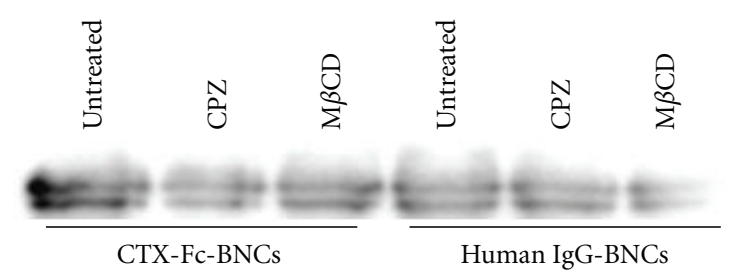

(a)

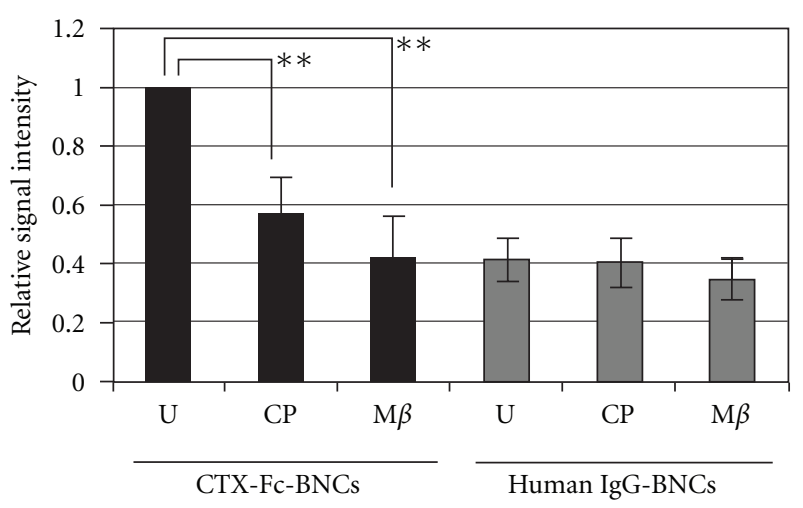

(b)

Figure 6: Assessment of the mechanism of CTX-Fc-BNCs internalization. A172 cells were treated with CTX-Fc-BNCs or human IgG$\mathrm{BNCs}$ in the presence of $100 \mathrm{nM} \mathrm{CPZ}$ or $5 \mathrm{mM} \mathrm{M} \beta \mathrm{CD}$ at $37^{\circ} \mathrm{C}$ for $1 \mathrm{~h}$, followed by trypsinization. The cytoplasmic fraction was immunoprecipitated with anti-HBsAg antibody conjugated to microbeads. "Untreated" indicates that the cells were treated with CTXFc-BNCs in the absence of any inhibitors. (a) The precipitates were immunoblotted and detected using anti-human-IgG-Fc antibody. (b) The BNC bands were analyzed densitometrically using a CS Analyzer 3.0 and plotted in each graph to evaluate the amount endocytosed. U: untreated; CP: CPZ; M $\beta: M \beta C D$. The data (mean \pm S.D) presented are from three independent experiments $\left({ }^{* *} P<0.05\right)$.

a cholesterol-dislodging oligosaccharide that inhibits caveolar formation and perturbs clathrin-coated endocytic vesicles $[35,36]$. Because $300 \mathrm{nM}$ CTX significantly reduced the green fluorescence of BNCs by competing with CTX-FcBNCs (Figure 5(a)), CTX-Fc-BNCs binding on A172 cell surfaces should be specific to the CTX-binding site such as MMP-2 and MT1-MMP. The internalization of CTX-FcBNCs was shown to be temperature dependent (Figure 5(b)). This suggests that cellular uptake of CTX-Fc-BNCs was receptor mediated.

Zhang et al. reported that CTX was displayed on polyethylene glycol (PEG-) coated iron oxide nanoparticles that were detectable in the tumor lesions of mouse and rat glioma models. They demonstrated the active targeting of glioma cells using a combination of CTX and supermagnetic or fluorescent compounds in vivo and in vitro [37-40]. CTX-displaying nanoparticles were able to pass the bloodbrain barrier (BBB) or the blood-tumor barrier (BTB) after intravenous injection and accumulated in brain tumors $[38,41]$. Many methods, such as intratumoral injection, intracavity injection, microdialysis, biodegradable polymers, and enhanced convection, have been used for local drug delivery to brain tumors [42]. Given the characteristic features of CTX-Fc-BNCs, the targeted intravenous injection of brain tumors with nanodrugs displaying CTX-Fcs should alleviate painful side effects in patients.

\section{Conclusions}

We designed a fusion protein between CTX and human IgG-Fcs. Depending on the presence of hinge region of Fc domain, the fusion protein exists as a monomer or a dimmer. The monomeric form, M-CTX-Fc, performed as an active targeting ligand to suppress the motility of A172 glioblastoma cells. We then constructed a protein nanocapsule displaying M-CTX-Fc as CTX-Fc-BNCs, which showed specific affinity to the surface of A172 cells and internalized into the cytoplasmic space. This internalization depended on the clathrin-mediated endocytosis pathway. Thus the internalization was enhanced by the multivalent display of the ligand on nanocapsules, which should be a promising drug delivery system for targeting glioblastoma when an appropriate anticancer agent is loaded.

\section{Conflict of Interests}

The authors report no conflict of interests. The authors alone are responsible for the content and writing of the paper.

\section{Acknowledgments}

This work was supported by a Grant-in-Aid for Scientific Research (B) from the Ministry of Education, Culture, Sports, Science and Technology of Japan (MEXT KAKENHI Grant no. 21300179) and by a Grant-in-Aid for Scientific Research (C) from the Japan Society for the Promotion of Science (JSPS KAKENHI Grant no. 24510151).

\section{References}

[1] A. Giese, R. Bjerkvig, M. E. Berens, and M. Westphal, "Cost of migration: invasion of malignant gliomas and implications for treatment," Journal of Clinical Oncology, vol. 21, no. 8, pp. 1624-1636, 2003.

[2] M. W. Roomi, V. Ivanov, T. Kalinovsky, A. Niedzwiecki, and M. Rath, "Inhibition of glioma cell line A-172 MMP activity and cell invasion in vitro by a nutrient mixture," Medical Oncology, vol. 24, no. 2, pp. 231-238, 2007.

[3] C. Wild-Bode, M. Weller, and W. Wick, "Molecular determinants of glioma cell migration and invasion," Journal of Neurosurgery, vol. 94, no. 6, pp. 978-984, 2001.

[4] A. T. J. Beliën, P. A. Paganetti, and M. E. Schwab, "Membranetype 1 matrix metalloprotease (MT1-MMP) enables invasive migration of glioma cells in central nervous system white 
matter," Journal of Cell Biology, vol. 144, no. 2, pp. 373-384, 1999.

[5] H. Sato and T. Takino, "Coordinate action of membranetype matrix metalloproteinase-1 (MT1-MMP) and MMP2 enhances pericellular proteolysis and invasion," Cancer Science, vol. 101, no. 4, pp. 843-847, 2010.

[6] S. Hernandez-Barrantes, M. Toth, M. M. Bernardo et al., "Binding of active $(57 \mathrm{kDa})$ membrane type 1-matrix metalloproteinase (MT1-MMP) to tissue inhibitor of metalloproteinase (TIMP)-2 regulates MT1-MMP processing and proMMP-2 activation," Journal of Biological Chemistry, vol. 275, no. 16, pp. 12080-12089, 2000.

[7] L. Emdad, P. Dent, D. Sarkar, and P. B. Fisher, "Future approaches for the therapy of malignant glioma: targeting genes mediating invasion," Future Oncology, vol. 8, pp. 343346, 2012.

[8] T. R. Alves, F. R. S. Lima, S. A. Kahn et al., "Glioblastoma cells: a heterogeneous and fatal tumor interacting with the parenchyma," Life Sciences, vol. 89, pp. 532-539, 2011.

[9] M. D. Groves, V. K. Puduvalli, K. R. Hess et al., "Phase II trial of temozolomide plus the matrix metalloproteinase inhibitor, marimastat, in recurrent and progressive glioblastoma multiforme," Journal of Clinical Oncology, vol. 20, no. 5, pp. 13831388, 2002.

[10] J. Yue, K. Zhang, and J. F. Chen, "Role of integrins in regulating proteases to mediate extracellular matrix remodeling," Cancer Microenvironment, vol. 5, no. 3, pp. 275-283, 2012.

[11] L. M. Coussens, B. Fingleton, and L. M. Matrisian, "Matrix metalloproteinase inhibitors and cancer: trials and tribulations," Science, vol. 295, no. 5564, pp. 2387-2392, 2002.

[12] J. A. DeBin, J. E. Maggio, and G. R. Strichartz, "Purification and characterization of chlorotoxin, a chloride channel ligand from the venom of the scorpion," American Journal of Physiology, vol. 264, no. 2, pp. C361-C369, 1993.

[13] J. Deshane, C. C. Garner, and H. Sontheimer, "Chlorotoxin inhibits glioma cell invasion via matrix metalloproteinase-2," Journal of Biological Chemistry, vol. 278, no. 6, pp. 4135-4144, 2003.

[14] L. Soroceanu, Y. Gillespie, M. B. Khazaeli, and H. Sontheimer, "Use of chlorotoxin for targeting of primary brain tumors," Cancer Research, vol. 58, no. 21, pp. 4871-4879, 1998.

[15] M. Veiseh, P. Gabikian, S. B. Bahrami et al., "Tumor paint: a chlorotoxin:Cy5.5 bioconjugate for intraoperative visualization of cancer foci," Cancer Research, vol. 67, no. 14, pp. 68826888, 2007.

[16] M. Akcan, M. R. Stroud, S. J. Hansen et al., "Chemical reengineering of chlorotoxin improves bioconjugation properties for tumor imaging and targeted therapy," Journal of Medicinal Chemistry, vol. 54, no. 3, pp. 782-787, 2011.

[17] D. Yu, T. Fukuda, Tuoya et al., "Engineered bio-nanocapsules, the selective vector for drug delivery system," IUBMB Life, vol. 58, no. 1, pp. 1-6, 2006.

[18] T. Yamada, Y. Iwasaki, H. Tada et al., "Nanoparticles for the delivery of genes and drugs to human hepatocytes," Nature Biotechnology, vol. 21, no. 8, pp. 885-890, 2003.

[19] Y. Tsutsui, K. Tomizawa, M. Nagita et al., "Development of bionanocapsules targeting brain tumors," Journal of Controlled Release, vol. 122, no. 2, pp. 159-164, 2007.

[20] A. Vaidyanath, T. Hashizume, T. Nagaoka et al., "Enhanced internalization of ErbB2 in SK-BR-3 cells with multivalent forms of an artificial ligand," Journal of Cellular and Molecular Medicine, vol. 15, pp. 2525-2538, 2011.

[21] T. Hashizume, T. Fukuda, T. Nagaoka et al., "Cell type dependent endocytic internalization of ErbB2 with an artificial peptide ligand that binds to ErbB2," Cell Biology International, vol. 32, no. 7, pp. 814-826, 2008.

[22] M. Thier, E. Roeb, B. Breuer, T. A. Bayer, H. Halfter, and J. Weis, "Expression of matrix metalloproteinase-2 in glial and neuronal tumor cell lines: inverse correlation with proliferation rate," Cancer Letters, vol. 149, no. 1-2, pp. 163170, 2000.

[23] H. Sato, T. Takino, Y. Okada et al., "A matrix metalloproteinase expressed on the surface of invasive tumour cells," Nature, vol. 370, no. 6484, pp. 61-65, 1994.

[24] S. Papparella, B. Restucci, O. Paciello, and P. Maiolino, "Expression of matrix metalloprotease-2 (MMP-2) and the activator membrane type 1 (MT1-MMP) in canine mammary carcinomas," Journal of Comparative Pathology, vol. 126, no. 4, pp. 271-276, 2002.

[25] R. Visse and H. Nagase, "Matrix metalloproteinases and tissue inhibitors of metalloproteinases: structure, function, and biochemistry," Circulation Research, vol. 92, no. 8, pp. 827-839, 2003.

[26] C. M. Overall, "Molecular determinants of metalloproteinase substrate specificity: matrix metalloproteinase substrate binding domains, modules, and exosites," Applied Biochemistry and Biotechnology, vol. 22, no. 1, pp. 51-86, 2002.

[27] E. M. Tam, T. B. Moore, G. S. Butler, and C. M. Overall, "Characterization of the distinct collagen binding, helicase and cleavage mechanisms of matrix metalloproteinase 2 and 14 (gelatinase A and MT1-MMP): the differential roles of the MMP hemopexin C domains and the MMP-2 fibronectin type II modules in collagen triple helicase activities," Journal of Biological Chemistry, vol. 279, no. 41, pp. 43336-43344, 2004.

[28] P. C. Brooks, S. Strömblad, L. C. Sanders et al., "Localization of matrix metalloproteinase MMP-2 to the surface of invasive cells by interaction with integrin $\alpha \mathrm{v} \beta 3$," Cell, vol. 85, no. 5, pp. 683-693, 1996.

[29] B. Hu, M. J. Jarzynka, P. Guo, Y. Imanishi, D. D. Schlaepfer, and S. Y. Cheng, "Angiopoietin 2 induces glioma cell invasion by stimulating matrix metalloprotease 2 expression through the $\alpha \mathrm{v} \beta 1$ integrin and focal adhesion kinase signaling pathway," Cancer Research, vol. 66, no. 2, pp. 775-783, 2006.

[30] K. Kessenbrock, V. Plaks, and Z. Werb, "Matrix metalloproteinases: regulators of the tumor microenvironment," Cell, vol. 141, no. 1, pp. 52-67, 2010.

[31] Y. Itoh and M. Seiki, "MT1-MMP: a potent modifier of pericellular microenvironment," Journal of Cellular Physiology, vol. 206, no. 1, pp. 1-8, 2006.

[32] A. Kwiatkowska, M. Kijewska, M. Lipko, U. Hibner, and B. Kaminska, "Downregulation of Akt and FAK phosphorylation reduces invasion of glioblastoma cells by impairment of MT1MMP shuttling to lamellipodia and downregulates MMPs expression," Biochimica et Biophysica Acta, vol. 1813, no. 5, pp. 655-667, 2011.

[33] P. Osenkowski, M. Toth, and R. Fridman, "Processing, shedding, and endocytosis of membrane type 1-Matrix metalloproteinase (MT1-MMP)," Journal of Cellular Physiology, vol. 200, no. 1, pp. 2-10, 2004.

[34] B. G. Gálvez, S. Matías-Román, M. Yáñez-Mó, F. SánchezMadrid, and A. G. Arroyo, "ECM regulates MT1-MMP localization with $\beta 1$ or $\alpha \mathrm{v} \beta 3$ integrins at distinct cell compartments modulating its internalization and activity on human endothelial cells," Journal of Cell Biology, vol. 159, no. 3, pp. 509-521, 2002.

[35] R. Chadda, M. T. Howes, S. J. Plowman, J. F. Hancock, R. G. Parton, and S. Mayor, "Cholesterol-sensitive Cdc42 activation 
regulates actin polymerization for endocytosis via the GEEC pathway," Traffic, vol. 8, no. 6, pp. 702-717, 2007.

[36] S. K. Rodal, G. Skretting, Ø. Garred, F. Vilhardt, B. Van Deurs, and K. Sandvig, "Extraction of cholesterol with methyl- $\beta$ cyclodextrin perturbs formation of clathrin-coated endocytic vesicles," Molecular Biology of the Cell, vol. 10, no. 4, pp. 961974, 1999.

[37] C. Sun, O. Veiseh, J. Gunn et al., "In vivo MRI detection of gliomas by chlorotoxin-conjugated superparamagnetic nanoprobes," Small, vol. 4, no. 3, pp. 372-379, 2008.

[38] O. Veiseh, C. Sun, C. Fang et al., "Specific targeting of brain tumors with an optical/magnetic resonance imaging nanoprobe across the blood-brain barrier," Cancer Research, vol. 69, no. 15, pp. 6200-6207, 2009.

[39] O. Veiseh, F. M. Kievit, J. W. Gunn, B. D. Ratner, and M. Zhang, "A ligand-mediated nanovector for targeted gene delivery and transfection in cancer cells," Biomaterials, vol. 30, no. 4, pp. 649-657, 2009.

[40] O. Veiseh, J. W. Gunn, F. M. Kievit et al., "Inhibition of tumor-cell invasion with chlorotoxin-bound superparamagnetic nanoparticles," Small, vol. 5, no. 2, pp. 256-264, 2009.

[41] R. Huang, W. Ke, L. Han, J. Li, S. Liu, and C. Jiang, "Targeted delivery of chlorotoxin-modified DNA-loaded nanoparticles to glioma via intravenous administration," Biomaterials, vol. 32, no. 9, pp. 2399-2406, 2011.

[42] D. R. Groothuis, "The blood-brain and blood-tumor barriers: a review of strategies for increasing drug delivery," NeuroOncology, vol. 2, no. 1, pp. 45-49, 2000. 

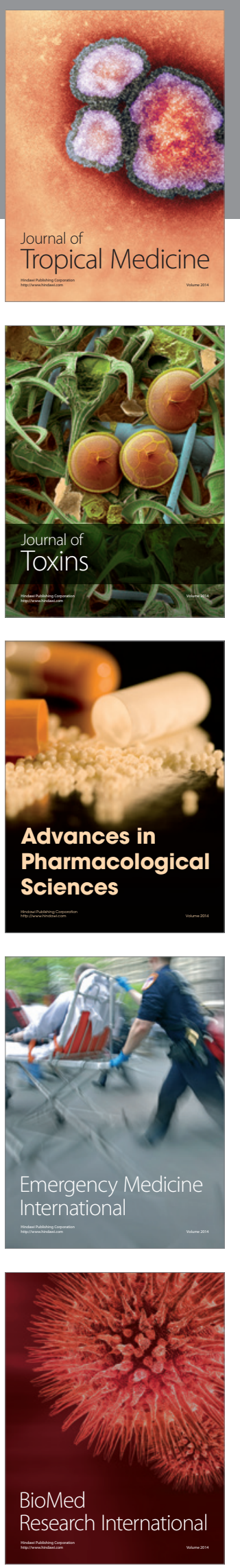
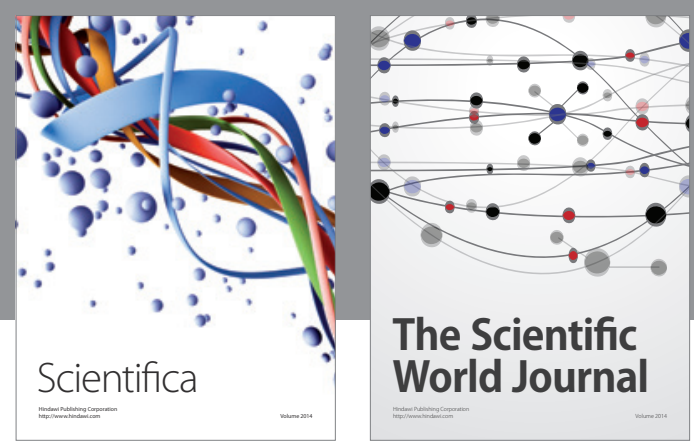

The Scientific World Journal
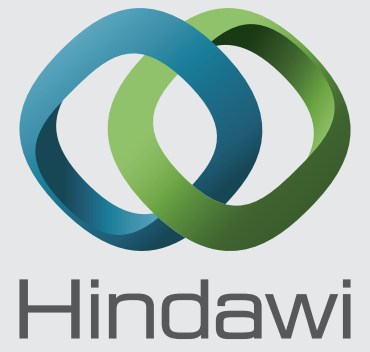

Submit your manuscripts at

http://www.hindawi.com
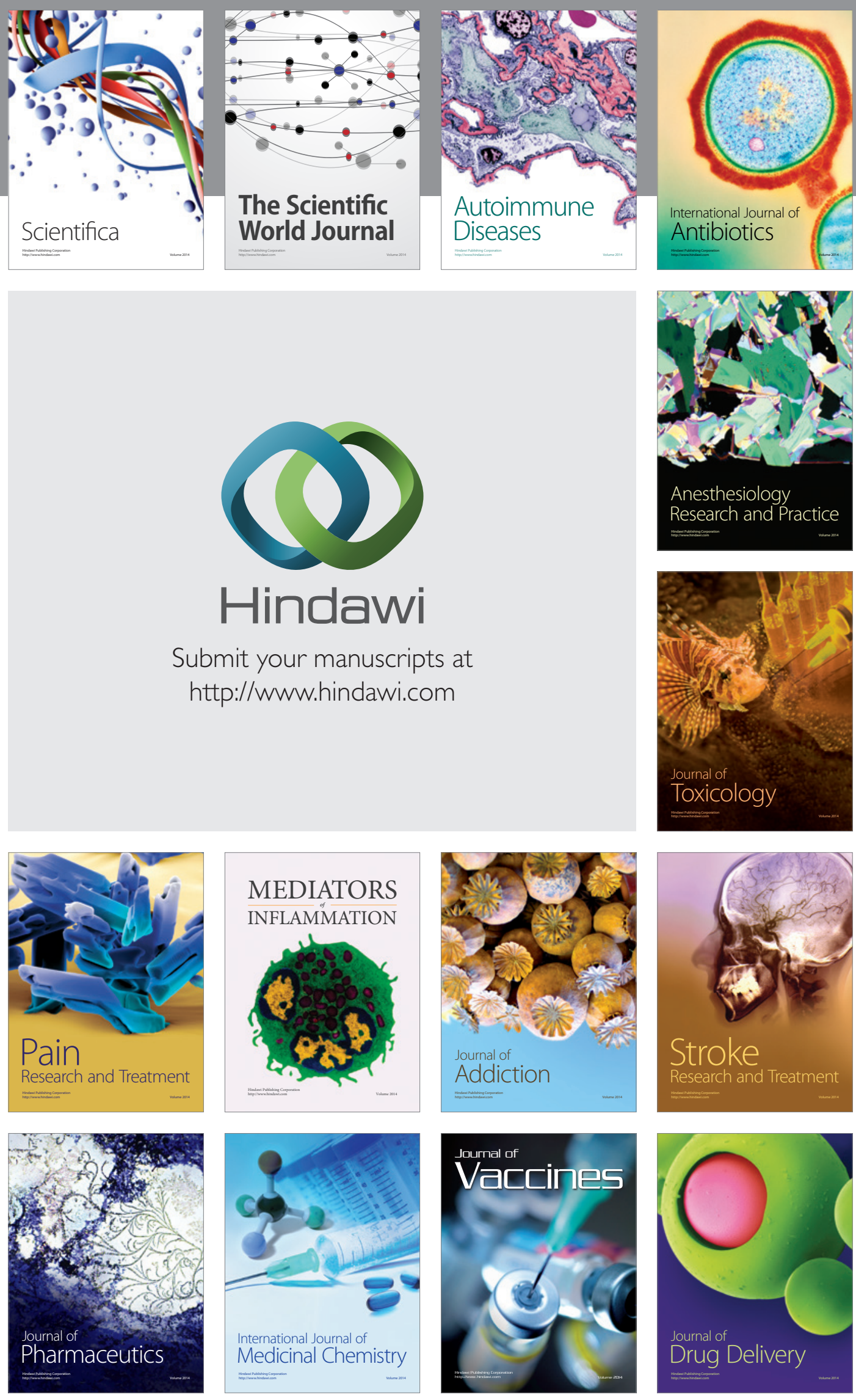